(2) Open Access Full Text Article

REVIEW

\title{
Impact of Bilateral versus Single Internal Thoracic Artery Grafting on the Long-Term Survival in Adults: A Systematic Review
}

\author{
Montaser Nabeeh Al Smady (iD) \\ Mohammed Nagdi Zaki (iD) \\ Eman Alataywi id \\ Olivier Jegaden ${ }^{2}$ \\ 'College of Medicine, Mohammed Bin \\ Rashid University of Medicine and Health \\ Sciences, Dubai, United Arab Emirates; \\ ${ }^{2}$ Cardiothoracic Surgery Department, \\ Mediclinic Airport Road Hospital, Abu \\ Dhabi, United Arab Emirates
}

\begin{abstract}
Objective: To analyse the survival of patients who had undergone bilateral internal thoracic artery grafting versus those with single internal thoracic artery grafting from the available literature. Moreover, this study will review the available literature regarding which of the two techniques seems to be the safest with long-term survival and reduced mortality rates.

Methods: A literature search of the databases was conducted to retrieve studies that fall under the study design of cohort and randomized controlled clinical trials in English from January 2015 to July 2021. Finally, seven studies were selected: four cohort studies and three other from a randomized trial.

Results: The cohort studies revealed that bilateral internal thoracic artery grafting is associated with lower mortality rates and better long-term survival outcomes than single internal thoracic artery grafting, while the ART randomized controlled clinical trials showed that there is no significant difference in mortality rates between both the coronary artery bypass grafting techniques. However, all studies concluded that bilateral internal thoracic artery grafting is associated with a higher frequency of deep sternal wound infections.

Conclusion: The discrepancy in results between the cohort studies and randomized controlled clinical trial remains persistent. However, the stated advantages of bilateral internal thoracic artery grafting are not strong enough to convince surgeons to alter their practice and the wide magnitude of expectations from the ART study was reckoned as inadequate. This may well be due to the presence of limited criteria for bilateral internal thoracic artery grafting in identifying the impact on survival of extended arterial revascularization, and there is a new colossal expectation from the ongoing randomized trial based on multiple arterial grafting versus single arterial grafting.
\end{abstract}

Keywords: coronary artery bypass grafting, coronary artery disease, internal thoracic artery, arterial revascularization, multiple arterial grafts

\section{Introduction}

\section{Background and Rationale}

Surgical coronary revascularization has been recognized for many years as the gold standard for the treatment of coronary heart disease and remains the most common cardiac surgery performed today worldwide. ${ }^{1,2}$ The use of the left internal thoracic artery (LITA) to bypass the left anterior descending coronary artery (LAD) has been a technique of reference since its positive impact on survival, which was demonstrated in comparison with other conduits, mainly vein graft. ${ }^{3}$ An incremental benefit has been expected from the use of the right internal thoracic artery
Correspondence: Montaser Nabeeh Al Smady; Olivier Jegaden

Email Montaseralsmadi@gmail.com;

Montaser.AISmady@students.mbru.ac.ae;

olivier.jegaden@mediclinic.ae 
(RITA) to supplement LITA; however, the hypothesis stating the superiority of bilateral internal thoracic artery (BITA) grafting over single internal thoracic artery (SITA) grafting due to a possible additional impact still remains controversial, despite the higher risk of deep sternal wound infections (DSWI) documented in BITA procedures. $^{4}$

\section{Purpose/Aim}

This Systematic review will analyse the available literature pertaining to which technique is the safest, most efficient and provides patients with the longest survival and lowest mortality rates. It aims to analyse both the use of BITA grafting and SITA. Furthermore, it addresses the operative and post-operative complications of each procedure.

\section{Objectives}

1. To analyse the survival rates between patients that had undergone BITA grafting VS SITA grafting from the available literature.

2. To analyse the operative and post-operative complications of both techniques.

3. To update the literature on the safest procedure with the lowest mortality rates.

\section{Methods}

This study is reported according to the preferred reporting items for Systematic reviews and Meta-Analyses (PRISMA) guidelines. ${ }^{5}$

\section{Study Design}

A systematic review was conducted on studies of Coronary Artery Bypass Grafting (CABG) in terms of the different techniques used and survival outcomes according to the PRISMA guidelines. In addition, a PRISMA flow chart was used to outline the search and selection of articles in this review.

\section{Search Strategy}

The electronic database, PubMed (MEDLINE) was searched to retrieve the required literature using the following MeSH search term: "Coronary Artery Bypass/ methods [MeSH Terms]".

Simultaneously, the search criteria involved the selection of articles within the last 5-year time frame as well as the inclusion of the specific study designs, which were randomized controlled clinical trials (RCTs) and comparative/observational studies specifically cohort studies.

\section{Eligibility Criteria}

The studies were included according to their compatibility with the following criteria:

1. Articles published in English.

2. Studies published between January 2015 and July 2021.

3. Published papers that are part of the same RCT, even if they were published prior to January 2015.

4. Study designs that were cohort studies (comparative/observational studies) and RCTs.

5. Studies that focused on the use of BITA and SITA grafts (or internal mammary arterial grafts) in adults.

\section{Study Selection}

Four authors independently screened the titles and abstracts of the compatible studies and identified duplicates were removed. Based on the initial screening of titles and abstracts, studies were identified and considered to be eligible for full-text review, in which they were retrieved from the electronic databases.

\section{Data Collection Process and Data Items}

The data extracted from the full-text articles that fulfilled the inclusion criteria is presented in a summary table demonstrating the following categories: Author Name, Year of Publication, Country, Study Design, Sample Size, and the following variables for SITA \& BITA: Number, Male gender, Mortality, Sternal complication, Sternal Reconstruction, Myocardial infarction, Stroke, Repeat revascularization, and the $\mathrm{p}$-value.

No ethical approval was required as this is a systematic review, which is based on studies that have already been published and are accessible to the public through electronic databases, journals and websites.

\section{Risk of Bias Amongst Studies}

This study is susceptible to language bias and selection bias, where language bias is indicated as only studies in English were included in this review. However, selection bias was minimized by the use of several databases as well as the review of titles, abstracts and full text by four authors independently.

\section{Results}

\section{The Literature Search}

Through various database search strategies, a total of 321 titles and abstracts were identified. Duplicate studies were 
removed, after which 306 articles remained. The 306 records were screened, and 299 of them were excluded due to ineligibility, leaving 7 articles for full-text article review. Ultimately, the 7 full-text articles completely satisfied the eligibility criteria and were included in the review. The PRISMA flowchart summarizing the data collection process is presented in Figure 1.

\section{Search Summary}

Seven studies were included in the review in accordance with the eligibility criteria, three published articles from the United Kingdom (UK), one from Australia and three from the United States of America (USA). The three articles from the UK belong to one RCT with a follow- up period of 1,5 and 10 years. The first paper was published in the year 2010. Hence, modifications to the inclusion criteria were necessary to include this article since it is a part of the follow-up of the ART study.

The essential data have been extracted from the seven studies, summarized and presented in Table 1.

\section{Discussion}

\section{Interpretation of Collected Data}

The ART study published by Taggart et al in the UK has been followed up for 10 years. ${ }^{6-8}$ It is a two-arm randomized multicenter clinical trial that was conducted across 7 countries involving 28 hospitals with the patients being equally distributed between the 2 procedure groups that

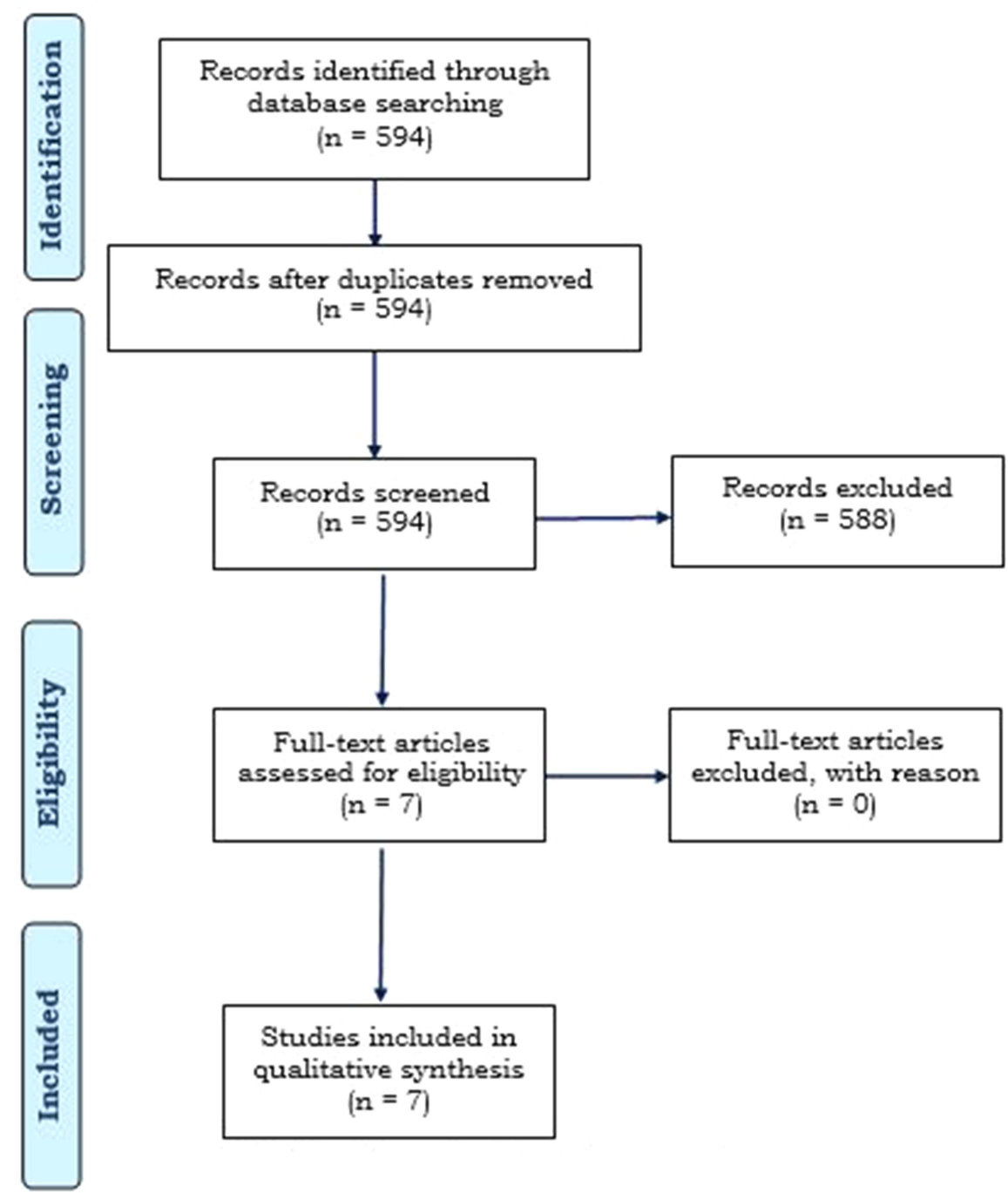

Figure I PRISMA flow diagram.

Note: Adapted from Moher D, Liberati A, Tetzlaff J, Altman DG, The PRISMA Group (2009). Preferred Reporting Items for Systematic Reviews and Meta-Analyses: The PRISMA Statement. PLoS Med 6(7): el000097. ${ }^{5}$ 
Table I Overview of Studies Analyzed Reporting Mortality, Sternal Complications and Major Adverse Events After Single (SITA) or Bilateral Internal Thoracic Artery Grafting (BITA) According to the Postoperative Follow-Up

\begin{tabular}{|c|c|c|c|c|c|c|c|}
\hline $\begin{array}{l}\text { Author (Year) [Ref.] } \\
\text { Country }\end{array}$ & $\begin{array}{c}\text { Sample Size (Male } \\
\text { Gender) }\end{array}$ & $\begin{array}{l}\text { Study } \\
\text { Design }\end{array}$ & $\begin{array}{c}\text { Mean } \\
\text { Follow-Up }\end{array}$ & Variables & SITA & BITA & p-value \\
\hline Taggart $(2010)^{6} \mathrm{UK}$ & $3102(85.6 \%)$ & $\mathrm{RCT}$ & I year & $\begin{array}{l}\text { Number } \\
\text { Male gender } \\
\text { Mortality } \\
\text { Sternal complication } \\
\text { Sternal Reconstruction } \\
\text { Myocardial infarction } \\
\text { Stroke } \\
\text { Repeat revascularization }\end{array}$ & $\begin{array}{c}1554 \\
86.1 \% \\
2.3 \% \\
1.9 \% \\
0.6 \% \\
2 \% \\
1.8 \% \\
1.3 \%\end{array}$ & $\begin{array}{c}1554 \\
85.1 \% \\
2.5 \% \\
3.5 \% \\
1.9 \% \\
2 \% \\
1.5 \% \\
1.8 \%\end{array}$ & $\begin{array}{c}- \\
- \\
N R \\
0.005 \\
0.002 \\
N R \\
N R \\
N R\end{array}$ \\
\hline Taggart $(2016)^{7}$ UK & $3102(85.6 \%)$ & RCT & 5 years & $\begin{array}{l}\text { Mortality } \\
\text { Myocardial infarction } \\
\text { Stroke } \\
\text { Repeat revascularization }\end{array}$ & $\begin{array}{l}8.4 \% \\
3.5 \% \\
3.2 \% \\
6.6 \% \\
\end{array}$ & $\begin{array}{l}8.7 \% \\
3.4 \% \\
2.5 \% \\
6.5 \%\end{array}$ & $\begin{array}{l}0.77 \\
0.86 \\
0.24 \\
0.91\end{array}$ \\
\hline Taggart $(2019)^{8}$ UK & $3102(85.6 \%)$ & RCT & 10 years & $\begin{array}{l}\text { Mortality } \\
\text { Myocardial infarction } \\
\text { Stroke } \\
\text { Repeat revascularization }\end{array}$ & $\begin{array}{c}21.2 \% \\
5 \% \\
4.9 \% \\
10 \%\end{array}$ & $\begin{array}{c}20.3 \% \\
4.6 \% \\
3.7 \% \\
10.3 \%\end{array}$ & $\begin{array}{l}0.62 \\
N R \\
N R \\
N R\end{array}$ \\
\hline $\begin{array}{l}\text { DeSimone }(2018)^{10} \\
\text { USA }\end{array}$ & $47,984(74.3 \%)$ & $\begin{array}{l}\text { Matched } \\
\text { cohorts }\end{array}$ & 12 years & $\begin{array}{l}\text { Number } \\
\text { Male gender } \\
\text { Early mortality } \\
\text { Mediastinitis }\end{array}$ & $\begin{array}{l}1297 \\
81 \% \\
1.2 \% \\
0.9 \%\end{array}$ & $\begin{array}{l}1297 \\
82 \% \\
0.8 \% \\
0.8 \%\end{array}$ & $\begin{array}{c}- \\
- \\
0.315 \\
0.667\end{array}$ \\
\hline Schwann (2018)' USA & I,493,470 (70.1\%) & Database & NR & $\begin{array}{l}\text { Number } \\
\text { Male gender } \\
\text { Early mortality } \\
\text { Mediastinitis }\end{array}$ & $\begin{array}{c}I, 334,5 \mid \mathrm{I} \\
73.8 \% \\
1.91 \% \\
0.73\end{array}$ & $\begin{array}{l}73,054 \\
85.1 \% \\
1.19 \% \\
1.08 \%\end{array}$ & $\begin{array}{c}- \\
<0.001 \\
<0.001 \\
<0.001\end{array}$ \\
\hline Shi $(2015)^{12}$ Australia & $282 ।(80 \%)$ & $\begin{array}{l}\text { Matched } \\
\text { cohorts }\end{array}$ & NR & $\begin{array}{l}\text { Number } \\
\text { Male gender } \\
\text { Early mortality } \\
\text { Mediastinitis }\end{array}$ & $\begin{array}{l}591 \\
88 \% \\
0.7 \% \\
0.8 \%\end{array}$ & $\begin{array}{l}591 \\
88 \% \\
1.2 \% \\
1.7 \%\end{array}$ & $\begin{array}{c}- \\
- \\
0.55 \\
0.30\end{array}$ \\
\hline $\begin{array}{l}\text { Samadashvili }(2019)^{13} \\
\text { USA }\end{array}$ & $63,402(76 \%)$ & $\begin{array}{l}\text { Matched } \\
\text { cohorts }\end{array}$ & I year & $\begin{array}{l}\text { Number } \\
\text { Male gender } \\
\text { Mortality } \\
\text { Myocardial infarction } \\
\text { Stroke } \\
\text { Repeat revascularization }\end{array}$ & $\begin{array}{c}10,828 \\
82 \% \\
2.2 \% \\
1.9 \% \\
1.7 \% \\
3.5 \%\end{array}$ & $\begin{array}{c}10,828 \\
83 \% \\
2.4 \% \\
1.6 \% \\
1.8 \% \\
2.5 \%\end{array}$ & $\begin{array}{c}- \\
- \\
0.26 \\
0.07 \\
0.29 \\
<0.001\end{array}$ \\
\hline & & & 7 years & $\begin{array}{l}\text { Mortality } \\
\text { Myocardial infarction } \\
\text { Stroke } \\
\text { Repeat revascularization }\end{array}$ & $\begin{array}{l}14.3 \% \\
6.2 \% \\
5.2 \% \\
14.6 \%\end{array}$ & $\begin{array}{l}12.7 \% \\
5.2 \% \\
5.4 \% \\
11.7 \%\end{array}$ & $\begin{array}{c}<0.001 \\
0.006 \\
0.78 \\
<0.001\end{array}$ \\
\hline
\end{tabular}

Notes: $\mathrm{p}$-value $<0.05=$ Statistical significance.

Abbreviations: RCT, randomised controlled clinical trial; NR, not reported.

are being compared, namely SITA and BITA grafts. The eligibility criteria were integrated into the patient selection process, which allowed the inclusion of patients with an existing multi-vessel coronary artery disease and undergoing CABG. However, patients with multi-vessel coronary artery disease with evolving myocardial infarction that need to have a redo $\mathrm{CABG}$ or require a single graft have been excluded. The SITA group received a SITA graft for the LAD along with a supplemental vein or radial artery to other coronary arteries. The BITA 
group received BITA grafts to the left-sided coronary arteries as they are quite important along with a supplemental radial artery or a vein to other coronary arteries. The primary outcome of the study was to compare mortality from all causes at 10 years of follow-up amongst patients in both the SITA and BITA procedure groups in a sample size of 3102 patients.

In the first paper published in $2010,{ }^{6}$ the main outcomes of the study were the clinical outcomes that presented at 30 days post-operation and at 1 year such as myocardial infarction, stroke, repeat revascularization and most importantly all-cause mortality. The data from this study were analyzed according to the intention-to-treat method, which is ideal in demonstrating the type of randomization where all the participants in the groups are analyzed according to the group they were originally assigned to irrespective of the actual treatments and events. From the 3102 patients, 1554 were in the SITA grafting group (1338 males and 216 females) and the remaining 1548 in the BITA group (1318 male and 230 female). 30-day mortality was recorded as $1.2 \%$ for both SITA \& BITA. After one-year follow-up and out of 1540 patients that had SITA grafts, the mortality rates were $2.3 \%$ and out of the 1529 that received BITA grafts the mortality rate was $2.5 \%$. The difference is statistically insignificant. The rates of myocardial infarction, repeat revascularization and stroke were quite similar at 30 days and 1-year time interval amongst both groups. Meanwhile, the incidence of sternal wound reconstruction was $0.6 \%$ and $1.9 \%$ for SITA \& BITA, respectively. Hence, it was thought that the use of BITA grafts is practical, but only routinely done or if deemed necessary based on the patient's medical state.

The second paper published in $2016^{7}$ with a 5 -year follow-up period demonstrated that the mortality frequency and rates of patients that underwent SITA grafting to be $130(8.4 \%)$ and of those who received BITA grafting to be $134 \%$ and $8.7 \%$. The p-value was calculated to be 0.77 , and thus there is no statistically significant difference in terms of mortality between SITA and BITA grafts. However, there were more sternal wound complications with BITA than with SITA grafting with a p-value $(<0.05)$ of 0.005 deeming the presence of a statistically significant difference. The post-operative complication was demonstrated, where the rates of sternal wound complication were $1.9 \%$ for SITA and $3.5 \%$ for BITA, with a rate of $0.6 \%$ and $1.9 \%$, respectively, for sternal wound reconstruction. Additionally, the rates and frequencies for myocardial infarction for SITA were $54(3.5 \%)$ and for BITA were $52(3.4 \%)$ and for stroke were 49 (3.2\%) and $38(2.5 \%)$, respectively.

The final paper in the ART study ${ }^{8}$ had a follow-up duration of 10 years, which demonstrated the mortality and frequency rates of SITA as $329(21.2 \%)$ and BITA to be $315(20.3 \%)$. The p-value is 0.62 hence there is no statistical significance between the mortality rates of BITA and SITA grafts. Overall, the ART study showed no statistically significant difference between the use of SITA and BITA grafts with regard to mortality frequency and rates. Conversely, it has shown that BITA grafting is linked with a higher incidence of sternal wound complications and reconstructions, which needs to be taken into account as it has the potential to increase patient mortality rates: ${ }^{9}$ rates of sternal wound complications were $1.9 \%$ for SITA and $3.5 \%$ for BITA, with a rate of $0.6 \%$ and $1.9 \%$, respectively, for sternal wound reconstruction. Additionally, the rates and frequencies for myocardial infarction for SITA were $78(5 \%)$ and for BITA were 71 (4.6\%) and for stroke were $76(4.9 \%)$ and 57 (3.7\%), respectively.

The fourth study was a cohort study by DeSimone et al ${ }^{10}$ that was conducted in the United States and published in 2018 with the primary endpoint of the study to be the follow-up outcomes at 10 years. The data were extracted from the NNECDSG open-heart registry and consisted of a sample size of 47,984 of which 35,663 were males and 12,320 were females. A total of 46,502 patients had undergone SITA grafting of which 34,575 were males and 12,044 were females. The results for both the SITA and BITA grafts were classified into crude (prior to propensity matching) and adjusted survival rates. In the crude comparison, the post-operative length of stay and in-hospital outcomes were better for BITA when compared to SITA grafts, with an early mortality rate of $2.0 \%$ for SITA and $0.9 \%$ for BITA grafts $(p=0.005)$. The overall survival was significantly better for BITA versus SITA $(\mathrm{P}<0.001)$. Although there was a great difference in the size of the groups $(46,502$ SITA and 1482 BITA), the propensity scores for both groups were almost within the same range. This indicated that no significant number of patients were excluded from the match because of scores that were too extreme. Finally, 1297 patients were propensity matched to a cohort of SITA patients, and there was no difference in early mortality and in-hospital outcomes for BITA versus SITA. For the propensity-matched cohort, the overall survival was still better for BITA versus SITA ( $\mathrm{p}=0.001)$. Additionally, the data 
were reanalysed using a 3:1 propensity match, along with a multivariable Cox model that included and excluded the propensity score and inverse probability weighting in order to strengthen the validity of the results, the same significant survival advantage with BITA was found with each statistical method. In the matched cohort, there was no survival advantage for up to 5 years. However, the survival curves began to separate afterwards and the absolute difference in survival was $8.4 \%$ at 15 years. In addition, BITA has a better survival benefit over SITA grafts amongst diabetic patients in the matched groups without increase in early adverse event. For patients aged younger than 70 years, survival was better with BITA, but not for those aged 70 years or older. In conclusion, the long-term survival was better in patients that received BITA grafts, along with no increase in short-term adverse effects. It was only after 5 years that survival benefits began to increase and persisted throughout the 15 years follow-up period.

The fifth study by Schwann et $\mathrm{al}^{11}$ is a cohort study that was conducted in the United States and published in 2018, where the primary outcome measures of the study were DSWI, operative mortality occurring during the initial hospitalization or within 30 days of the operation. The data were extracted from the Society of Thoracic Surgeons Adult Cardiac Surgery Database (STS ACDS), and a sample size of 1,493,470 CABG patients from 1255 hospitals was included. Out of which 1,334,511 (89.4\%) received Single arterial Bypass Graft as SITA, 73,054 (4.9\%) had BITA grafting and the remaining had SITA associated with Radial artery grafting. With respect to the operative outcomes, third-day mortality data were not available for 199,247 SITA (14.9\%) and 12,275 for BITA $(16.8 \%)$ and as such were excluded from the analysis. Observed operative mortality frequency and the rate was significantly lower for BITA than for SITA: 722 $(1.19 \%)$ vs $21,708(1.91 \%)$, respectively, with $\mathrm{p}<0.001$. DSWI rates were more frequent amongst patients that undertook BITA grafts than SITA graft: $1.08 \%$ vs $0.73 \%$, respectively, with $\mathrm{p}<0.001$. Median postoperative stay rates were lower for BITA grafting when compared to SITA. It is important to emphasize that propensity score matching was not conducted during the analysis in the study, deeming the bias present in this study overpowering and making it less reliable to compare with the other studies.

The sixth study by Shi et $\mathrm{al}^{12}$ is a cohort study that was conducted in Australia and published in 2015, and the patient data were extracted from a multicenter database.
The database provided demographics of patients in details, operative technique, postoperative hospital course, preoperative risk factors and the clinical outcomes including but not limited to 30-day or in-hospital morbidity and mortality. The data were collected prospectively, and the survival status of the patients was extracted from the National Death Index, which is limited to record all the deaths that have only occurred within Australia. However, the study sample was selective of patients that had undergone a surgery from January 1995 to December 2010 which resulted in a sample of 11,840 patients. After applying the inclusion and exclusion criteria to match the requirements of the study, the outcome was a cohort consisting of 2821 patients, of which 1909 received an SITA graft and the remaining 912 received a BITA graft, and the survival data were obtained from the national death index. The primary outcomes measured by this study were long-term survival which was possible to record through the Australian National Death Index. Additionally, mortality rates at 30-days post operation and DSWI were observed. The 30-day mortality frequencies were quite similar where SITA $(27,1.4 \%)$ and BITA $(10,1.1 \%)$ with a p-value of 0.60 . Long-term survival rates at 15 years were much higher in BITA $(80 \%)$ than in SITA $(53 \%)$ with $\mathrm{P}<0.001$. Due to the presence of selection bias amongst patients receiving BITA owing to the fact that the patients were younger and less likely to have several risk factors, such as cerebrovascular disease, peripheral vascular disease, diabetes, chronic obstructive pulmonary disease, and a higher proportion of male patients, a propensity score-matched analysis comparing the two techniques, was performed in order to minimize bias. In the propensity score-matched analysis, 591 matched pairs were assigned, the rates were similar for the following 30-day mortality SITA (4, 0.7\%), BITA (7, $1.2 \%),[\mathrm{p}=0.55]$ and DSWI $(5,0.8 \%)$ Vs $(10,1.7 \%)$, $[\mathrm{p}=0.30]$. The mortality rates at 15 years for BITA were associated with a better risk-adjusted survival (79\%) than with SITA $(67 \%)$ with a $\mathrm{p}<0.001$.

The seventh and final study in this review by Samadashvili et $\mathrm{al}^{13}$ is a cohort study conducted in the USA and published in 2019. The New York's Cardiac surgery reporting system (CSRS) and New York's Vital Statistics file databases were used in this study to extract patient records and data. The study was restricted to the residents of the state of New York to minimize the possibility of post-discharge outcomes arising outside the state of New York. A sample size of 63,402 patients was 
included in this study out of which 50,773 (80\%) received Single arterial graft (SAG) and 12,629 (20\%) received Multiple Arterial Grafts (MAG). The study outcomes were mortality rates at 1 and 7 years along with sternal wound infections. The data for these outcomes were not stated in the paper for the original sample size. Propensity score matching was conducted as to minimize the selection bias present by identifying a set of SAG/MAG pairs that were matched according to several patient-based risk factors. The outcome of the propensity score matching was 21,656 patients; 10,828 pairs of matched patients for SAG and MAG. As commonly seen in MAG, the patients that had undergone the procedure experienced higher rates of sternal wound infections $(1.01 \%$ vs $0.62 \%, \mathrm{p}=0.002)$. There was no significant difference in 1-year mortality between MAG and SAG $(2.4 \%$ vs $2.2 \%, \mathrm{p}=0.26)$. At 7-years, the mortality was $12.7 \%$ vs $14.3 \%$ for MAG and SAG respectively $(\mathrm{p}<0.001)$. This lower mortality at 7-year in favor of MAG was not observed in patients older than 70 years, having 2-vessel disease with right coronary artery disease, an off-pump surgery, an acute myocardial infarction within 20 days prior to the surgery and renal dysfunction. Further sensitivity analysis was conducted after the exclusion of cases that did not undergo complete revascularization, the 7-year mortality remained significantly less for MAG when compared to SAG $(11.5 \%$ vs $13 \%$, respectively, $p<0.001)$. In this cohort, it was identified that there was no statistical difference in the 1-year mortality rates between the MAG and the SAG, which is presumed to indicate that the selection bias was minimized by propensity score matching. In contrast, 7-year mortality and major adverse cardiac event (MACE) were significantly lower in MAG compared to SAG.

\section{Summary of Major Findings}

The most recent cohort studies within the past 5-year time frame state that the use of BITA grafts is associated with lower mortality rates and increased long-term survival rates when compared to SITA grafts, but higher incidence of DSWI and prolonged procedure time leading to less frequent usage. ${ }^{10,11,14}$ The study outcomes of the most recently updated RCT illustrate that there is no significant difference in mortality rates between SITA and BITA grafting, yet it has also been shown that there is a higher risk of DSWI associated with BITA when compared to SITA grafting. ${ }^{6-8}$ The ART study concluded that there was no difference in mortality between BITA (20.3\%) and SITA (21.2\%); additionally there was no significant difference MACE where the percentage was $24.9 \%$ for BITA and $27.3 \%$ for SITA. ${ }^{8}$ There are a few potential reasons as to why the cohort study findings do not correspond to the ART study. Initially, the SITA group in the ART study, which represented $21.8 \%$ of the sample size also included patients that had received a radial artery graft, which has been established to be superior to saphenous vein grafts ${ }^{15}$ and this has been recognized by the authors of the ART study. Moreover, it could be presumed to be a key confounding factor as it is likely to enhance the SITA group through the addition of an arterial graft to the second most important artery. Interestingly, in the cohort study comparing SAG and MAG, ${ }^{13}$ the association of internal thoracic artery and radial artery grafts were included in the MAG group, resulting in a lower mortality in MAG group, which corresponds to the ART study as well. Secondly, in the ART patients $13.9 \%$ of the BITA group had undergone SITA while being assigned to the BITA group, resulting in a significant difference in favour of BITA in the as-treated analysis. $^{8}$ Additionally, the ART study ${ }^{6-8}$ had strict compliances with the guidelines-directed medical therapy, which presumably narrowed the differences in the outcomes amongst the 2 groups. Finally, an approximate of $40 \%$ of the procedures conducted in the ART study were conducted in an off pump setting, in contrast to $18 \%$ with the cohort study by Samadashvili et al. ${ }^{13}$ It is important to reiterate that bias due to the lack of variables in the registry of this cohort study could not be eliminated, some of these variables include life expectancy, access to care, graft compatibility of the target vessels and general life. Several published articles have concluded on specific conditions that have addressed which procedure is superior to the other in terms of improved long-term survival outcomes. In case of diabetic patients, it has been proven that the use of BITA grafts provides superior long-term survival outcomes. ${ }^{16,17}$ Nonetheless, it has been emphasized that the risk of DSWI is highly associated with BITA grafts as it is a more invasive procedure when compared to SITA grafts. ${ }^{16}$ Additionally, the general consensus is that BITA grafts should be avoided in elderly patients as they are associated with poor outcomes when compared to SITA. ${ }^{18}$ However, BITA grafts could be performed on the elderly patients if they fill specific criteria, such as lack of specific significant baseline co-morbidities, long life expectancy and have stable coronary artery disease. ${ }^{19}$ 


\section{Comparison with Previous Studies}

Previous systematic and literature reviews were focused on cohort studies that used data from registries, where both the cohort studies individually and the systematic reviews that relied on them cannot take into account confounder's data, which affects the validity of the results. The literature search only revealed the presence of a recently updated RCT with a long follow-up period of 10 years, which, as a result, led to the inclusion of cohort studies in this review. In this review, only cohort studies with propensityscore-matched analysis were selected to minimize bias. Furthermore, it sheds light on the lack of recent sufficient randomized controlled clinical trials that compare the use of SITA to BITA grafting.

\section{Implications for Public Health}

\section{Practitioners/Clinicians/Educators}

While the superiority of SITA and BITA remains contradictory with regard to long-term survival outcomes, clinicians tend to perform more SITA procedures as they are considered to be less invasive, have a shorter operative duration than BITA, shorter time under anaesthesia and shorter healing time post-op. Conducting more randomized controlled clinical trials with long follow-up periods and large groups of patients addressing this topic will provide updated data that will potentially reveal which procedure is superior to the other. Furthermore, it will also allow confounding data to be considered and analysed, which further strengthens the validity of the results obtained from the trials compared to cohort studies and cohort study-based systematic reviews.

\section{Strengths, Limitations, and Generalisability}

The strengths of this study are the analysis of the variation in results between cohort studies and a randomized controlled clinical trial pertaining to a certain topic and how this variation has led to the existence and persistence of conflict. Although randomized controlled clinical trials are minimally used in systematic reviews, this review attempted to focus and emphasize on them as they are classified as the leading type of study in the field of medical research. In essence, until this very day, clinicians and researchers cannot completely agree on whether SITA or BITA grafting is superior to the other in terms of survival rates.

Limitations of this study would be the presence of language bias as only studies in English were included without considering the relevance of papers in other languages. Only recent cohort studies were selected in order to be contemporary of the ART study with a similar follow-up, and also to avoid repetition with previous reviews. Moreover, the lack of ample recent RCTs pertains to their absence in the literature and emphasizes the desideratum of conducting more RCTs to be able to identify the most superior $\mathrm{CABG}$ technique.

\section{Areas for Future Research}

This study highlights that the debate is still ongoing. ART study failed to demonstrate the benefit of BITA mainly because of the diversity of the surgical configuration and technique in arterial revascularization (cross-over, additional arterial graft, off-pump). Recent studies have suggested that the debate between SITA and BITA could possibly be outdated. Moreover, the great emphasis on comparing SITA and MAG was beneficial in the sense that it helped to integrate the diversity of grafts configuration and the different technicalities that go into it. ${ }^{20,21}$

A new randomized study "The ROMA trial" (Randomized Comparison of the Clinical Outcome of Single Versus Multiple Arterial Grafts), comparing single and multiple arterial grafts is in process, started in January 2018 with primary completion end of 2021 and estimated completion date January $2030 .^{22}$ The findings of this study are estimated to resolve this conflict and provide the clarity needed.

\section{Conclusion}

The cohort studies show that BITA grafting is associated with an overall superior long-term survival outcome when compared to SITA grafting. However, the ART randomized controlled clinical trial demonstrated that there is no significant difference between the use of SITA and BITA grafts with regard to long-term survival outcomes. In addition, the risk of DSWI is highly associated with BITA when compared to SITA grafts as proven by the data from the studies. Due to the restricting and involute nature of the BITA grafting criteria, attempting to identify the impact on survival of extended arterial revascularization was deemed challenging. This places new ongoing randomized trials under the spotlight to aid in concluding the debate of MAG vs SAG.

\section{Abbreviations}

CABG, coronary artery bypass grafting; SITA, single internal thoracic artery; ITA, internal thoracic artery; SAG, single arterial graft/grafting; BITA, bilateral internal 
thoracic artery; MAG, multiple arterial grafts/grafting; RCT, randomized controlled trial; DSWI, deep sternal wound infection; MACE, major adverse cardiac events.

\section{Ethical Approval}

All procedures performed in studies involving human participants were in accordance with the ethical standards of the institutional and/or national research committee and with the 1964 Helsinki declaration and its later amendments or comparable ethical standards.

\section{Ethical Clearance}

The Institutional Ethics Committee (IRB) approved the study.

\section{Acknowledgments}

We would like to thank Dr. Tom Loney and Prof. Stefan Du Plessis for their valuable contribution and guidance. The abstract of this paper was presented at the "Third Annual Mediclinic Middle East Research day" as a poster presentation with interim findings. The poster's abstract was published in "Poster Abstracts" in Medicine Journal: https://journals.lww. com/md-journal/Fulltext/2020/06120/Third_annual_ Mediclinic Middle East Research Day .1.aspx. The manuscript has not been presented or published anywhere.

\section{Funding}

For this type of study, funding is not required.

\section{Disclosure}

The authors declare that they have no conflicts of interest in this work.

\section{References}

1. Squiers J, Mack M. Coronary artery bypass grafting-fifty years of quality initiatives since Favaloro. Ann Cardiothorac Surg. 2018;7 (4):516-520. doi:10.21037/acs.2018.05.13

2. Melly L, Torregrossa G, Lee T, Jansens J, Puskas J. Fifty years of coronary artery bypass grafting. J Thorac Dis. 2018;10(3):1960-1967. doi: $10.21037 / \mathrm{jtd} .2018 .02 .43$

3. Cuminetti G, Gelsomino S, Curello S, Lorusso R, Maessen J, Hoorntje J. Contemporary use of arterial and venous conduits in coronary artery bypass grafting: anatomical, functional and clinical aspects. Netherlands Heart J. 2016;25(1):4-13. doi:10.1007/s12471016-0919-2

4. Marasco S. Total arterial revascularization. Operative Tech Thorac Cardiovasc Surg. 2016;21(1):20-30. doi:10.1053/j.optechstcvs.20 16.08.002

5. Moher D, Liberati A, Tetzlaff J, Altman DG. Preferred reporting items for systematic reviews and meta-analyses: the PRISMA statement PLoS Med. 2009;6(7):e1000097. doi:10.1371/journal.pmed.1000097
6. Taggart D, Altman D, Gray A, et al. Randomized trial to compare bilateral vs. single internal mammary coronary artery bypass grafting: 1-year results of the Arterial Revascularisation Trial (ART). Eur Heart J. 2010;31(20):2470-2481. doi:10.1093/eurheartj/ehq318

7. Taggart D, Altman D, Gray A, et al. Randomized trial of bilateral versus single internal-thoracic-artery grafts. $N$ Engl J Med. 2016;375 (26):2540-2549. doi:10.1056/NEJMoa1610021

8. Taggart D, Benedetto U, Gerry S, et al. Bilateral versus single internal-thoracic-artery grafts at 10 years. $N$ Engl J Med. 2019;380 (5):437-446. doi:10.1056/NEJMoa1808783

9. Lu J. Risk factors for sternal wound infection and mid-term survival following coronary artery bypass surgery. Eur J Cardiothorac Surg. 2003;23(6):943-949. doi:10.1016/S1010-7940(03)00137-4

10. DeSimone J, Malenka D, Weldner P, et al. Coronary revascularization with single versus bilateral mammary arteries: is it time to change? Ann Thorac Surg. 2018;106(2):466-472. doi:10.1016/j.athoracsur.20 18.01.089

11. Schwann T, Habib R, Wallace A, et al. Operative outcomes of multiple-arterial versus single-arterial coronary bypass grafting. Ann Thorac Surg. 2018;105(4):1109-1119. doi:10.1016/j.athoracsur.20 17.10.058

12. Shi W, Hayward P, Tatoulis J, et al. Are all forms of total arterial revascularization equal? A comparison of single versus bilateral internal thoracic artery grafting strategies. $J$ Thorac Cardiovasc Surg. 2015;150(6):1526-1534.e3. doi:10.1016/j.jtcvs.2015.05.074

13. Samadashvili Z, Sundt T, Wechsler A, et al. Multiple versus single arterial coronary bypass graft surgery for multivessel disease. $J$ Am Coll Cardiol. 2019;74(10):1275-1285. doi:10.1016/j.jacc.20 19.06.067

14. Ejiofor J, Kaneko T, Aranki S. Current readings: single vs bilateral internal mammary artery in coronary artery bypass grafting. Sem Thorac Cardiovasc Surg. 2018;30(4):398-405. doi:10.1053/j. semtcvs.2018.05.004

15. Gaudino M, Benedetto U, Fremes S, et al. Radial-artery or saphenous-vein grafts in coronary-artery bypass surgery. $N$ Engl J Med. 2018;378(22):2069-2077. doi:10.1056/NEJMoa1716026

16. Puskas J, Sadiq A, Vassiliades T, Kilgo P, Lattouf O. Bilateral internal thoracic artery grafting is associated with significantly improved long-term survival, even among diabetic patients. Ann Thorac Surg. 2012;94(3):710-716. doi:10.1016/j.athoracsur.2012.03.082

17. Pevni D, Medalion B, Mohr R, et al. Should bilateral internal thoracic artery grafting be used in patients with diabetes mellitus? Ann Thorac Surg. 2017;103(2):551-558. doi:10.1016/j.athoracsur.2016.06.044

18. Kurlansky P, Traad E, Dorman M, Galbut D, Ebra G. Bilateral versus single internal mammary artery grafting in the elderly: long-term survival benefit. Ann Thorac Surg. 2015;100(4):1374-1382. doi:10.1016/j.athoracsur.2015.04.019

19. Rubino A, Gatti G, Reichart D, et al. Early outcome of bilateral versus single internal mammary artery grafting in the elderly. Ann Thorac Surg. 2018;105(6):1717-1723. doi:10.1016/j. athoracsur.2017.11.079

20. Jegaden OJL, Farhat F, Jegaden MPO, Hassan A, Lapeze J, Eker A. How decisive is the number of distal anastomoses in coronary bypass surgery? J CardioThorac Surg. 2021;16:6-15. doi:10.1186/s13019020-01384-9

21. Taggart DP, Gaudino MF, Gerry S, et al. Effect of total arterial grafting in the arterial revascularization trial. $J$ Thorac Cardiovasc Surg. 2021. doi:10.1016/J.JTCVS.2020.03.013

22. Gaudino M, Alexander JH, Bakaeen FG, et al. Randomized comparison of the clinical outcome of single versus multiple arterial grafts: the ROMA trial-rationale and study protocol. Eur J Cardiothorac Surg. 2017;52:1031-1040. doi:10.1093/ejcts/ezx358 


\section{Publish your work in this journal}

Vascular Health and Risk Management is an international, peerreviewed journal of therapeutics and risk management, focusing on concise rapid reporting of clinical studies on the processes involved in the maintenance of vascular health; the monitoring, prevention and treatment of vascular disease and its sequelae; and the involvement of metabolic disorders, particularly diabetes. This journal is indexed on PubMed Central and MedLine. The manuscript management system is completely online and includes a very quick and fair peerreview system, which is all easy to use. Visit http://www.dovepress. com/testimonials.php to read real quotes from published authors. 